\title{
Designing on-site: Facilitating participatory contextual architecture with mobile phones
}

\author{
Mikael B. Skov*, Jesper Kjeldskov, Jeni Paay, Niels Husted, Jacob Nørskov, Kenneth Pedersen \\ Centre for Socio-Interactive Design, Aalborg University, Department of Computer Science, Selma Lagerlö fs Vej 300, DK-9220 Alborg East, Denmark
}

\section{A R T I C L E I N F O}

\section{Article history:}

Available online $\mathrm{xxxx}$

\section{Keywords:}

Context

Architecture

Mobile devices

Field study

\begin{abstract}
A B S T R A C T
Some movements within modern architecture particularly emphasise the importance of matching buildings to their surroundings. However, practicing such "contextual architecture" is highly challenging and typically not something the future inhabitants of a building are well equipped for participating in. This paper explores the potentials of using mobile phone technology for facilitating such client participation in the parts of an architecture process that take place on the building site. For this we introduce ArchiLens, a mobile system for interactive on-site 3D visualisation of houses, and findings from a field study with 40 participants in the process of building or modifying their home. The study showed that using the system helped evoke people's imagination of the look and feel of their future house, and envision it in context. This enabled them to participate more closely in the design process on-site by iteratively reviewing design alternatives and exploring, for example, other placements and materials.
\end{abstract}

(c) 2012 Elsevier B.V. All rights reserved.

\section{Introduction}

As articulated by the famous Finnish architect Eliel Saarinan "one should always design a thing by considering it in its next larger context-a chair in a room, a room in a house, a house in an environment, an environment in a city plan". This view represents a movement within modern architecture that particularly emphasises the importance of working closely with the context in which a building is going to be located. This design philosophy has given rise to several highly acclaimed buildings around the world praised by their inhabitants for the way they fit naturally with their surroundings. However, practicing such "contextual architecture" [1-3] is a challenging undertaking for even the best architects, and is typically not something that architects' clients - the future house owners or inhabitants - can easily participate in. One of the reasons for this is that exploring different architectural possibilities on the site where a building is going to be built requires highly developed skills of visual imagination often exceeding those of a non-architecturally trained person. Also, mock-ups or small-scale physical models of future homes or houses are quite complex and expensive and typically not something one would do for smaller development projects like family houses. Typically, current approaches to house development would involve sketches (paper or computer) and a number of $2 \mathrm{D}$ or $3 \mathrm{D}$ computer models of the future house that future house owners can interact with and make changes to. But usually it is difficult to carry out such work in context. Thus, to complement more traditional architecture and to practice contextual architecture, we need new tools that can help people stimulate their imagination while participating in such a design activity.

Augmented reality (AR) allows superimposing digital graphics on the real world and thereby creating a visual blend between the real and the virtual [4]. Key promises from this technology are that such composite scenes on mobile devices can enrich the experience of a physical space [5]. Until now real-time processing of 3D models and camera feeds have been

\footnotetext{
* Corresponding author. Tel.: +45 9949 8922; fax: +45 99409798.

E-mail address: dubois@cs.aau.dk (M.B. Skov).
} 


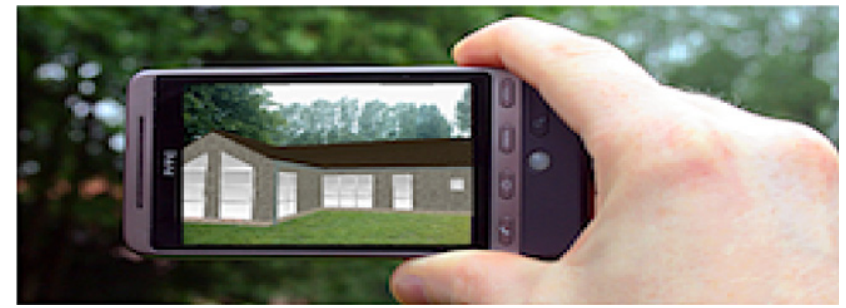

Fig. 1. Visualising architecture in context on a mobile phone while standing at the building site.

problematic on mobile devices due to limited performance. However, with recent leaps in smart phone technology, such as higher CPU power, better displays and cameras, and spatial sensors like GPS and compasses, designers are now able to make advanced mobile AR applications available to ordinary people without requiring special and expensive hardware.

As an interesting area of application, we have been exploring how mobile AR can be used to facilitate ordinary people's participation in architectural design by evoking their imagination. For this purpose we have developed a mobile AR system, ArchiLens, which supports on-site interactive 3D visualisation of buildings on a mobile phone (Fig. 1). The use of the system was investigated through a field study with 40 participants in the process of building or modifying their home, allowing them to explore and review design alternatives while present in its physical context.

\section{Related work}

Our research is grounded in two main bodies of related work. The first is Contextual architecture. Contextual architecture (e.g. $[1,3,6])$, also referred to as contextualism [7], represents a design philosophy where the interplay between form and context is given particular priority. Apart from having a notable effect on the produced outcomes, working within this design philosophy has some profound impacts on the process of design. Architects working closely with the context of their buildings spend significant time developing and assessing their design on the building site rather than at the drawing board in their studio. As an example, it is a well-known fact that the Danish architect Jørn Utzon, who is probably best known for the Sydney Opera House, spent considerable time on building lots exploring their contextual properties before and during the development of his building designs. In a rare interview he even described how he would sometimes map out the possible location of walls and windows by placing lines of small rocks on the ground, and then walk around the lot imagining the view of the surrounding environment from these as yet un-built rooms. An account of the works of Sydney contextual architect Alex Popov (a former associate of Utzon's) describes how the result of buildings created with such sensitivity to the way they engage with their surrounding environment is that they do not just fit their context well, they themselves become parts of that evolving context [2].

In architectural theory, contextual architecture is described as a matter of pursuing the notion of genius loci (the protective spirit of a place in classical Roman religion) by responding to the topographical, geographical, social and cultural context of a building site [2]. This concept is most notably explored by Norwegian architect and theorist Christian Norberg-Schulz in his phenomenology of architecture [8] arguing that genius loci - or sensitivity to context - has profound implications for place making. Echoing this line of thought, American architect Christopher Alexander argues that architecture exhibiting a quality of timelessness always evolves through a series of "wholeness preserving transformations" in which the designer has not only focused on the creation of new forms but also done this with deep understanding of and respect for the existing context [9]. Alexander's Pattern Language [10] contains a collection of problem-solution pairs composed to help in evoking the reader's imagination of the elements of a future design in context - enabling architects, as well as ordinary people building or modifying their home, to achieve such wholeness preserving contextual architecture.

The other body of related work is Augmented Reality. Augmented reality (AR) was coined as a term in the early 1990s and has its origins in virtual reality, where computer graphics completely immersed users in synthetic worlds or environments [11]. However, where virtual reality disconnects the user from the physical world, AR superimposes virtual objects onto it [12].

Research in AR has explored various application domains and different technologies. There are several examples of tour guide applications such as in the ARCO project [13] where objects in a museum were augmented digitally, transforming the visitors from passive viewers and readers into active actors and players. Other examples include restaurant guides $[14,15]$, other museums guides [16], and general guides for tourists [17,18]. Another common application domain for AR is visualisation of hidden or invisible information. Examples of this include the SiteLens system, which visualises carbon monoxide levels in the user's immediate surroundings [19], and the use of AR for visualising hidden wires inside Boeing aircraft in support of the manual manufacturing process [20,21]. Finally, and of particular relevance to the work presented here, AR has been used for visualising architecture in situ, with a number of studies investigating the strengths and limitations of this application domain. In an early piece of AR research, Guo et al. describe the presentation of buildings as one of the main features of this technology [22]. As their example they describe the ARCHEOGUIDE system where Greek researchers and the government used AR to visualise the Grecian Olympia [22]. In an example of working with present construction projects, Schall et al. present an AR system using 3D models of underground infrastructure superimposed on the construction site [23]. 
While these and other research projects indicate that AR holds promising potentials for visualising architecture, technology shortcomings have so far limited use in practice [18,24]. Two issues of particular importance are accuracy of positioning and perception of depth. As examples, during outdoor testing, Schall et al. experienced several problems related to shortcomings of GPS tracking resulting in poor accuracy for workers in street canyons [23]. The same problem was reported by Reitmayr and Schmalstieg [18]. The issue of depth perception is reported by, amongst others, Schall et al. [23] who experienced that some users had problems with perceiving the overlaid graphical representation of infrastructure buried under ground correctly. This is an issue related to registration, which is a cornerstone for achieving successful utilisation of AR generally [12], and in particular when visualising architecture. The challenge of registration is that objects in the real and virtual worlds must be accurately aligned; otherwise the illusion that the two worlds coexist will be compromised. Key sources of registration errors include optical distortion, poor positioning, mechanical misalignment and incorrect viewing parameters. This obviously motivates technology improvements, but the effect of suboptimal registration can also be reduced if users have good spatial understanding or perception [12].

As a consequence of the technological challenges of visualising architecture in AR, previous research studies are dominated by the use of relatively advanced hardware setups during trials [14,15,23], while the use of off-the-shelf mobile devices is rarely seen. This means that although promising results may have been achieved in these trials, real-world use of the developed applications by non-experts has not been realistic. However, in recent years smart phones have begun to meet the basic requirements for AR in terms of processing power, positioning, display size and camera resolution. With AR technically within reach of the general population there is an opportunity for developing applications for real-world use as seen with Wikitude [25] and Layar [26]. One such application, we speculate, is the use of AR for enabling private homeowners, or people in the process of building their future house, to participate more actively in a contextualised design process through an interactive visualisation on their mobile phones. Exploring this idea, we have developed and deployed ArchiLens for evoking people's visual imagination and enabling them to explore and make decisions about placement, appearance, shape, and size of the building in context.

\section{ArchiLens}

We designed and implemented ArchiLens - a mobile application that integrates AR and 3D visualisation. The application places a 3D house model in context, overlaid on the camera feed on a smart phone, making it possible for users to examine future house designs from different angles by moving around physically on the site. ArchiLens was implemented for a HTC Hero Smartphone running Android 1.5 platform. The device has a screen with a resolution of $320 \times 480$ and hardware accelerated 3D graphics using OpenGL ES 1.0. ArchiLens utilizes the GPS in the phone for spatial placement, the phone digital compass and accelerometer for direction, and the built-in camera. Interaction with the device mainly takes place via a capacitive touch screen and a series of hardware buttons. Programming for the device was done in Java by using Eclipse IDE paired with the official Android API and plugins. The 3D house models were created in Google SketchUp and exported to OBJ format. A file parser algorithm was constructed to import the OBJ information into OpenGL. This made the turn-around time of making models smaller, since no extra care would have to be taken once the algorithm was in place. This faster creation of models was needed for all the different personalised models used in the user study. This enabled that users could browse between different house models, and that house models could be created based on real blueprints and models from involved participants' construction process.

As illustrated in $[17,18]$, poor accuracy can be a potential problem when using GPS for positioning. This was also a challenge for our GPS readings for positioning the house on Google Maps. At first, we experimented using Kalman filtering (e.g. [27]) that utilises a series of measurements over time to estimate a more precise result than those measurements based on a single measure. However, we found that this Kalman filter was actually too effective when moving around a lot (as you would do using ArchiLens). Therefore, we implemented our own smoothing algorithm that calculates the average of the last three GPS readings. On the other hand, the orientation sensor system in the HTC Smartphone is rather precise and updates extremely frequently. This introduces an issue with drawing the overlaid model, since it would jump around the screen. Again we experimented with different strategies for making the application precise and accurate, and ended up using our own smoothing algorithm on top of the sensor data to keep the house more static. Fig. 2 depicts the key views in ArchiLens, and in the use scenario we illustrate a typical situation. After this, we describe three central parts of ArchiLens' functionality: two-dimensional placement, spatial layout and characteristics, and visual appearance.

Use scenario: John and Kate want to build a house where they can live with their children. They visit a lot for sale. Arriving at the lot, they start ArchiLens and choose a house model. They now place the house on the virtual representation of the lot. ArchiLens visualises the house based on their preferences.

While walking around the lot, John gets different perspectives on how their choices fit into the surroundings. He notices all the neighbours have red bricks, and that their house is yellow. To see how their house would fit into the surroundings with red bricks, he changes materials through ArchiLens. He is surprised to see how the house changes with the new bricks. It nearly vanishes into the surroundings. John confers with Kate about the chosen colours. In cooperation, they decide that their initial idea about the yellow bricks is the best solution.

Kate notices that a neighbour's house is quite close to their panorama windows in the living room. She uses the blueprint drawing in ArchiLens to position herself at the panorama inside the virtual living room. She starts to check how the neighbour's house impacts their view from the living room and to her disappointment she realises that the neighbour's house totally blocks the view. They are therefore forced to rethink the position and orientation of their house. 


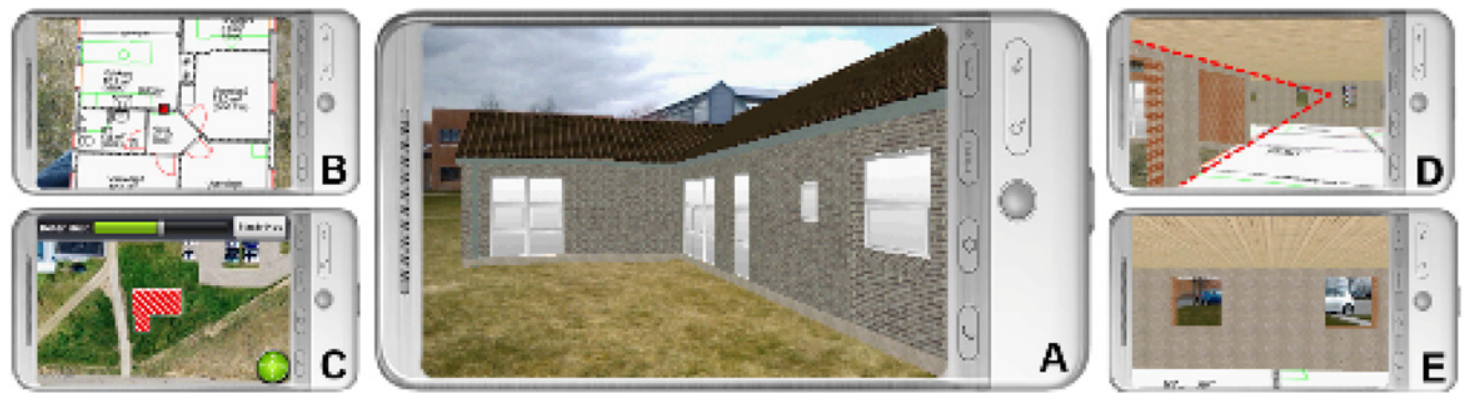

Fig. 2. ArchiLens. A: Screen capture of a virtual house positioned on a lawn. B: Screen capture of the Blueprint View, showing a general overview of the floor plan. The red square represents the user's position on the blueprint. C: Placement View for house placement and rotation. The red shape represents the house, and touching the screen makes it possible to rotate the house. D: View from inside the house. Notice the added dashed dividing lines between the roof and walls moving inwards and thereby creating perspective. E: Future view through the windows of the living room. Notice how the physical surroundings are visible through the windows in the virtual walls. (For interpretation of the references to colour in this figure legend, the reader is referred to the web version of this article.)

\subsection{Two-dimensional placement}

When the user has chosen a house model, the first step is to place it on the lot. ArchiLens supports this through a separate two-dimensional placement view using Google Maps. In this view, a visual link is created between the ArchiLens system and the user's physical surroundings by overlaying a proportionally correct outline of the house model on a satellite image (see Fig. 2(C)). Two main interactions are then available to the user. They can change the position of the house by moving it to any location on the Google map - the map adjusts and the house remains centred in the screen view. Using an on-screen control the user can also rotate the house around its centre point. When the user is happy with the placement the application changes to a 3D view, but at any point in time the user can go back to the placement view and re-position or rotate the house model.

\subsection{Spatial layout and characteristics}

ArchiLens uses GPS positioning and orientation sensors to create an illusion of moving around the house and viewing it from different angles (see Fig. 2(A)). The GPS coordinates for the house and for the user are used to calculate the position of the house relative to the user. The calculation involves the distance to and bearing between these two points. In order to determine camera orientation, the built-in sensors provide information about how the phone is rotated according to azimuth, pitch, and roll.

The visualisation of the virtual house has two different views that the user can alternate between by holding the phone horizontally with the camera facing the ground or vertically with the camera facing the horizon. We call the view presented when held vertical "3D View" (shown in Fig. 2(A)) and the view presented when held horizontally "Blueprint View" (Fig. 2(B)). In Blueprint View, the red square in the centre of the screen marks the user's position in relation to the house.

\subsection{The visual appearance}

ArchiLens allows the user to change the visual appearance of the house while standing on the lot and to explore the use of alternative building materials, including brick type, roof type, colour of the windows, doors and woodwork. This is done by activating a menu on the screen, selecting the element to modify, and browsing through the available options by swiping the screen from left to right. When a different material is selected, it is passed along the rendering pipeline and the specific segment of the house model will change texture in the 3D view.

\section{Field studies}

We studied the use of ArchiLens through a 5-week field study in spring 2010. The purpose of the study was to explore how ArchiLens evoked the imagination of ordinary homebuilders or renovators when given an interactive AR representation of their future house on the building site. In order to achieve diversity in feedback on the use of ArchiLens for different user groups, the field study involved participants from three different phases of building and modifying a private home: (1) open lot, (2) signed contract, and (3) house extension. Open lot is the phase where people want to build a new house, but have not yet initiated the actual design or construction process. Instead they are searching for a suitable piece of land and to get overall ideas about possible house locations and positioning. Signed contract is the phase where people have bought the lot and made a contract with a construction company to build their house. Hence, they are now in the process of having their house built, and might like to be actively involved in the process. Finally, house extension is the phase where current 
homeowners wish to extend their existing house. They are therefore interested in how the new extension will align with the old part of the house, as well as the surroundings. This group may or may not have a contract with a construction company.

\subsection{Participants}

Forty people (including 11 children) from 14 families participated in the field study over a combined period of 5 weeks. The adults aged from 28 to 41 with the majority in their mid-thirties. Participants were recruited and grouped in respect to the three phases of building.

\subsubsection{Open lot}

Twelve adults and two children from six different families participated in this group. During Open House or Open Lot events in the vicinity of Aalborg, families were asked to be a part of the study. They were approached when leaving these events held by local house development companies. Participants in this category usually only had vague ideas of their building criteria. Therefore they sought inspiration on house designs and most of them did not yet own land for the house. These participants were presented with variations of tract houses made by a house development company called "Vendia-Huset".

\subsubsection{Signed contract}

Twelve adults and six children from six families participated in this group. These participants all owned a vacant lot and had either signed a contract with Vendia-Huset for a specific house, or were in the process of signing. All families had seen floor plans of their houses, and three of them had also seen front elevation drawings. One family even had a 3D drawing of their future house. All participants were in their mid-thirties with young children. For this group of participants we received individual house blueprints from Vendia-Huset and created corresponding 3D models with possible choices of materials for the families to explore through ArchiLens.

\subsubsection{House extension}

Five adults and three children, from two families were recruited into this group, based on their wish to make a house extension. One of the adults was the designated architect for both families. Both families had ground plans and different drawings of their planned house extensions. These plans, models, and possible choices of materials were turned into corresponding 3D models viewable in ArchiLens.

\subsection{Procedure and data collection}

All field study sessions were conducted in situ at the user's own lot or at a lot that was for sale (if the participant was part of the Open Lot group). In total, we conducted 16 field sessions, as two families from the signed contract group participated in two sessions each. Each session in the field lasted between 10 and $65 \mathrm{~min}$ (most around $45 \mathrm{~min}$ ) with participants from the signed contract group generally spending more time with the system than others. Typically, the open lot participants would spent between 10 and 15 min using the application to explore different views of a house (and changing texture of the house), while signed contract participants would spend more than 30 min trying to perceive and understand their future house.

The participants were given a short presentation of the system and the purpose of the study. They were then asked to fill out a questionnaire and take part in a semi-structured interview. We then encouraged them to explore their house through ArchiLens by walking around the 3D house placed on the lot. A facilitator and an observer followed each group of participants, at a distance. The facilitator's role was to help with any problems and to probe for thoughts and comments from the participants. The observer noted down comments, actions, and interactions during the trial. When the participants had finished using the system, another questionnaire was handed out and a final interview was conducted to explore their experience and use of the system. Two families from the signed contract group wished to participate in a second session with a different 3D model altered on the basis of their input and requests from the first session. These sessions followed the same procedure.

Four months after the field trials, we conducted follow-up interviews with the families from the signed contract group to investigate their experiences of the built house. At this stage all six houses for this group were fully completed and most of the families had recently moved in. We conducted the post-construction interview to put the families' initial experiences of ArchiLens into perspective. In particular, we sought to understand how well the completed house matched their envisioned house, and what role ArchiLens had played in evoking and shaping their visualisation.

For the field study as a whole, we collected multiple types of data: questionnaires, written notes, video recordings and voice recordings. The first questionnaire asked for demographic data and responses to four general assertions using a five point Likert scale. Interviews were recorded in audio files, and families using the system were recorded on digital video. Researcher observations were described in notes. The second questionnaire consisted of the same four general assertions and specific statements regarding the use of ArchiLens, with a five point Likert scale for responses. 


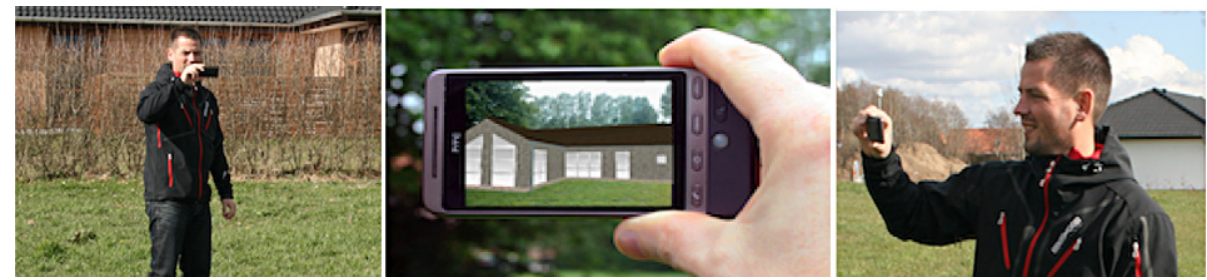

Fig. 3. People achieved a better understanding of the visual appearance of their future house when using ArchiLens.

\subsection{Data analysis}

The data analysis followed a Grounded Theory approach [28] to identify and classify identities and relations. Themes were generated by systematic use of techniques and procedures to divide the qualitative data into controllable elements before using this foundation to create higher-level concepts. Transcripts of the recordings and written researcher notes were analysed concurrently. First, open coding was used to discover 362 different properties, which identified 41 phenomena. Second, axial coding was used to create structure in the data and make categories based on the phenomena. Fourteen categories were derived from the phenomena. Third, selective coding was used to relate the categories to each other, with the purpose of gaining an understanding of how the categories were interrelated and to find the main themes. This resulted in four themes: (1) enhancing visual perception, (2) priming imagination in context, (3) collective social understanding, and (4) dimensional insight.

Questionnaire answers were then compared with the four themes, distilled from the notes and interviews, looking for convergence between the two.

\section{Findings}

The following sections report the findings from our field study. This section is organised according to the four themes emerging from the data analysis.

\subsection{Visual appearance}

Our participants were generally very interested in exploring the visual appearance of their future house. Several of them spent considerable time viewing the house from different angles when it was projected onto the building site through ArchiLens. Furthermore, some of the participants stated that they had problems in perceiving more traditional blueprints and imagining what different shapes and materials would look like on-site: "I simply don't like blueprints, I don't understand them ... while this is much easier to understand" [A].

Exploring the possibilities of ArchiLens made them appreciate that seeing their future house on the building site and being able to move around it in context made a huge difference on their visualisation of it (as illustrated in Fig. 3). As a related finding we observed that ArchiLens helped uncover areas where the participants' conception of the current design was incorrect or incomplete. This can, for example, be seen in the following comment made by a participant, who prior to trying ArchiLens had expressed that she had a very good visualisation of her future house: "I actually thought I had a good idea of how my house was going to look, but there were things that surprised me and helped me understand a few things. All because I could see the house from different angles" [B]. When we conducted the post-construction interview with her four months later, just after she had moved into the house, she followed up on this statement and expressed that in contrast to the blueprints the visualisation evoked by ArchiLens was very well aligned with how the house eventually looked.

Overall, most participants felt that they had achieved a better visualisation from using the system. In fact, many participants were surprised to realise that what they saw on the display when walking around the lot did not really match their imagination. One of the things they learned was that they didn't have a correct sense of the scale of the building as a whole. This was clearly reflected in the second questionnaire where they were asked, for a second time, to grade their visualisation of the house. Here, several participants expressed that they had scored this item too high in the first questionnaire. Consequently average scores for the question "It is easy for me to visualize the facades and appearance of the house on the lot" moved from 3 before using ArchiLens to 4.5 after.

Visualising the house in context also had a huge effect on how the participants bonded with their future home. As one participant stated while standing at the location of her future living room: "This is so cool, that I can stand here in my living room and imagine what views I will have" $[\mathrm{C}]$. Such bonding and understanding had reportedly been difficult using traditional blueprints or elevation drawings as people found it difficult to create mental images of the house in context on the basis of such drawings. Being able to see the house visually, and in its real physical surroundings, from the exact spot of interest supported this experience. The importance of the surroundings was also highlighted in a session where the camera feed suddenly turned off. This immediately caused the participant to comment that the experience was spoiled, and ask us to fix the device because they weren't finished exploring the house. 


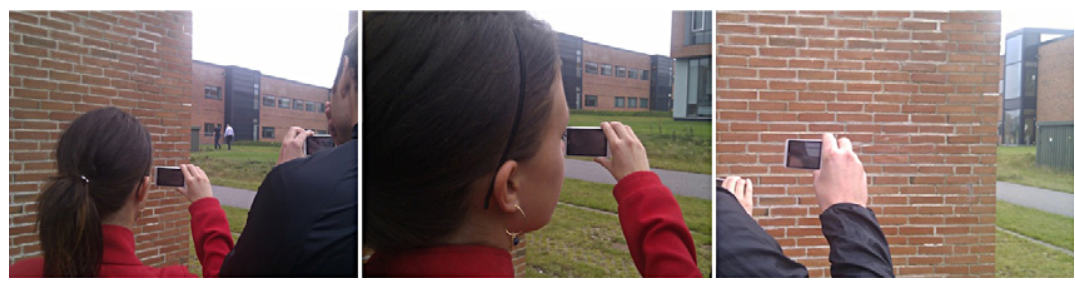

Fig. 4. Participants experiencing problems with visualising a house extension related to inaccurate 3D registration.

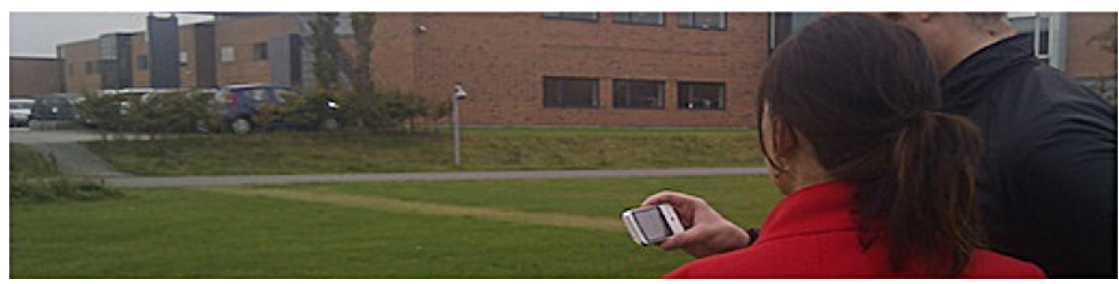

Fig. 5. Participants trying to understand contextual influences of nearby houses.

Two of the families participated in two sessions on their lot. One of these families used the second session to review the redesign of a carport, which had emerged from the first session, as well as other changes. This active participation in the design process and single iteration of changes helped them develop their understanding and imagination of physical movement around the house: "We have talked about how quick we would be able to drive into the carport from the road-we were afraid it would be too 'racing like'. But now that I can see it from here, I actually don't think it is going to be a problem" [D].

Somewhat surprisingly, 3D registration (the accuracy of the visualisation) was not a major concern for most participants. However, for the house extension group, this did cause some problems, and some participants were not satisfied with ArchiLens' ability to display this. In terms of extensions it was obvious that the system's current 3D registration accuracy simply wasn't good enough for seamlessly integrating a 3D model alongside an existing physical structure. This resulted in some major difficulties maintaining the illusion of an augmented reality along the walls and corners of existing buildings (Fig. 4).

\subsection{Relationship to context}

Visualising the house on the actual lot served as a primer for the participants to consider the interplay between their house and its surroundings. This was evident in the participants' intentions and behaviour when investigating the appearance of their house in its physical surroundings, and the appearance of these surroundings from the house.

Building and moving into a new house involves not only getting to know a new location and house, but often also getting acquainted with new neighbours. During observations and interviews, we observed several times that participants focused on challenges concerning the views of and from their neighbour's house as illustrated by this statement: "When we chose the lot and position of the house, we thought a lot about how the house should be orientated-Will the view be directly into the neighbouring bedroom?" [D].

Hence, several participants used ArchiLens to investigate and understand the orientation and placement of their house, and especially its windows, in relation to their neighbours (see Fig. 5). As an example, the use of ArchiLens made one family become aware of how close their house was going to be to their neighbours. Exploring this further, the father realised that their bathroom window was directly in front of a big window in the living room of a neighbour. To better understand the extent of these two issues, he first used ArchiLens to check the view from their bathroom window from inside the house. He then walked over to the adjoining lot and checked out how his house would appear from the neighbour's living room. Such detailed investigation in context enabled the future inhabitants to consider how position and orientation impacted not only the surroundings but also how the surroundings made an impact on their house, thereby helping them to make more informed design decisions.

For good reasons, the detailed interplay with neighbouring houses was not observed for participants where the neighbouring lots had not yet been sold, or did not have a planned house on them. It was also not an issue for any of the open lot participants, who were at this stage more interested in the visual appearance of the different basic house options, and their overall relation to surroundings.

Changing the setting of decision-making and visualisation, from being in an office to being on-site influenced the process. Participants obtained new understandings and got new ideas for alternative solutions, sometimes even overriding previous design decisions. One of the couples from the signed contract group used the ArchiLens session to consider their selection of materials: "I actually think I was confirmed in my choices, when I tried changing the bricks to some of the colours, we had talked about. I compared them to the surroundings and they simply did not work, so clearly our yellow bricks fit better than 


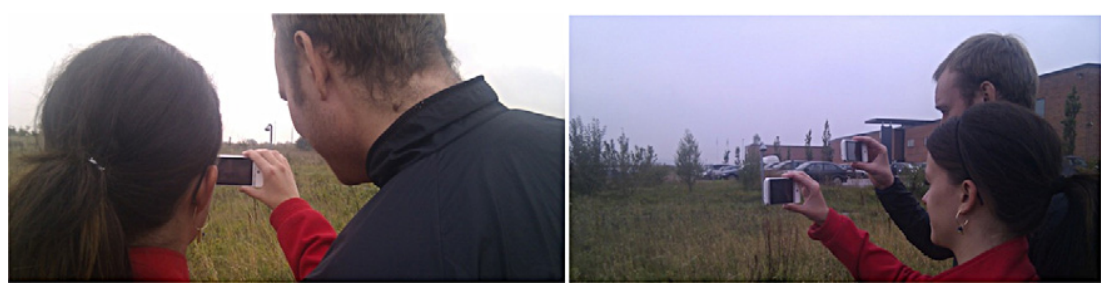

Fig. 6. A couple obtaining a collective understanding of their future home through ArchiLens.

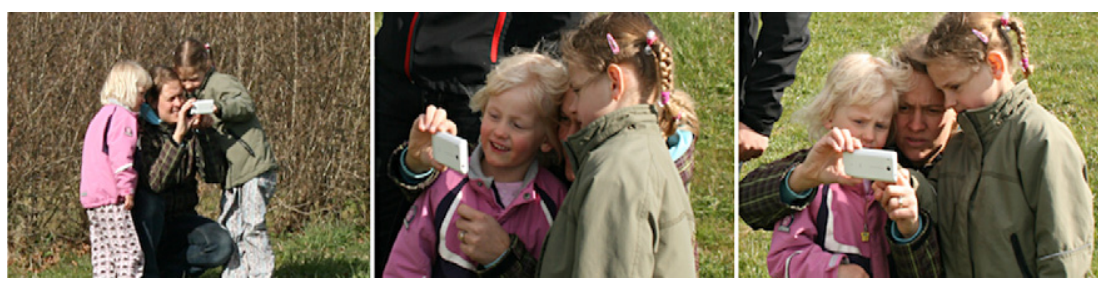

Fig. 7. Parents showing their future house to the children and pointing out their bedrooms.

black" [B]. Here the participant used ArchiLens as a tool for verifying decisions in context. She later confirmed this decision in the post-construction interview. It also showed that the couple did not want to stand out from their neighbours. As newcomers they wanted to fit in with the architectural style of the area.

Other couples started questioning some of their earlier decisions when they noticed different possible solutions. In most cases this happened when one of them was looking at a specific detail of the house, mostly about how the roof or some section of windows could be designed. One of the couples had the following considerations while using the system: "Come take a look at this. Should we maybe have used some more money and removed that wall? The others' (neighbouring houses) solutions look really smart" [B]. Later, this couple confirmed this change in the post-interview after their house was completed, expressing happiness that they had changed their original design. This illustrates how ArchiLens served as a primer for discussing and investigating the contextual influence, and in some cases made participants change their earlier decisions. As a female participant said: "It makes you think about a lot of things, when you can walk around and see the house" [D]. This included everything from how the garden should be laid out, where and how large the windows should be, to where the plugs for the TV should be placed in the living room.

Somewhat surprisingly, none of the participants from the signed contract group attempted to move the house to a new position on the lot. As a possible explanation we learned from the interviews that the families in this group were under restrictions in this respect, as most of them had chosen a house of the maximum size allowed by local building regulations, greatly reducing possible placements within allowed distances from boundaries and the road.

\subsection{Collective understanding}

Building a new house affects the whole family, but several participants stated that it was difficult to share opinions and negotiate details. We experienced that most participants got a refined mutual understanding while using ArchiLens. In fact, the visualisation in context and the dynamics of using ArchiLens gave them a shared point of reference. It facilitated a universal understanding between the involved parties: parents, children, friends, families, and architects. We discovered several interesting social interactions during our sessions. Couples interacted with each other to exchange information, to get feedback on material or placement changes, or to co-discover the house using ArchiLens (as in Fig. 6 where a couple is discussing their experience).

It seemed quite clear that couples strived to obtain a shared understanding of the house-as expressed by participants: "I could imagine it would make it easier to reach an agreement about details, because you discuss based on the same foundation ... the only thing I could have wanted, was to have had this system earlier in the process, as there at that point was many disputed points" [E].

ArchiLens also primed social interaction between parents and children. More of the participating families had children and as soon as children were present parents involved them by showing their future bedroom and what view they would have (as illustrated in Fig. 7).

The children indicated that they thought it was amazing to see this visual representation of their bedrooms. Their parents were also quite pleased to be able to involve the children in the process-this gave them an explanation tool to directly illustrate matters that they had discussed earlier.

Another social aspect was the need to present the house to other people for affirmation or acknowledgment of decisions. It became evident that a lot of couples had presented their ideas and blueprints to friends and families. But there was one major problem when doing this, as explained by one participant: "We have been out with friends to look at their building 


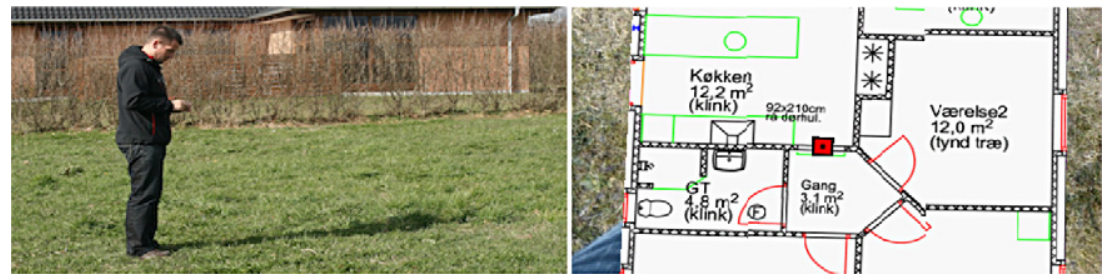

Fig. 8. Walking around the lot while using the dynamically updated position on the blueprint to understand dimensions.

project. They proudly presented their blueprints at the lot, but it's simply impossible to get more than a vague idea on how it's going to look from that" [D]. ArchiLens was mentioned as a great tool in such situations and several participants asked for the possibility to borrow the system either for decision-making or presentation to friends.

\subsection{Dimensional insight}

The one-to-one mapping of physical movements of the user while using ArchiLens gave them a more genuine understanding of the dimensions of their house by requiring them to explore it in its actual size. Most participants expressed that prior to trying ArchiLens they would usually sit around a table or in front of a computer looking at blueprints or 3D models. In such settings participants reportedly often experienced a poor sense of scale due to either difficulties in transforming sizes like $10 \mathrm{~cm}$ on a drawing to its actual size of $10 \mathrm{~m}$ in the real world, or difficulties in imagining the realworld size of a 3D model on a computer screen. As one participant revealed: "A 3D house model on a computer screen appear smaller than in the real world" [F].

This poor sense of scale led to a general wish for using ArchiLens to gain a better understanding of the physical size of the building in reality. This led to a common behaviour (among the male participants) of pacing out the size of the house, and how close it was going be to boundaries, while looking at the blueprint view (Fig. 8).

Many participants indicated that the practice of physically walking around the lot was the most important aspect of using the system for improving their dimensional understanding of the house. This was detailed with comments like: “....it was a lot easier to understand when you were in it (the physical surroundings)" [E] or "... it is great to 'touch' the house with my body" [F].

Understanding dimensions and size was difficult to many of our participants. Several stated that the blueprints only gave a partial understanding of the sizes of, for example, bedrooms, and the post-construction interviews revealed that one of the participants had imagined the bedrooms smaller than they actually were when the house was built. In this case, the system had only given her limited support.

\section{Discussion}

Our field studies of ArchiLens led to a number of interesting observations about the use of mobile technology in architectural design and development. The participating families were generally quite enthusiastic and positive towards using the system and towards the idea of being able to see and explore their future house on their mobile phone in its real future surroundings. In the field sessions most of them engaged quite extensively in the interaction, and in the follow-up interviews they applauded the practical value of the system as a tool for evoking their imagination and enabling them to participate in the architectural design process. In the following we will discuss these overall observations in a bit more detail.

\subsection{Evoking imagination}

Through the use of ArchiLens, we tried to facilitate people visualising images of their future house in their minds. We have referred to this as evoking their imagination as a part of forming new ideas or adjusting existing ones. Evoking imagination serves an important role in house design and development. This usually involves envisaging what the house, or a part of it, is going to look like, where it should be placed, how it will integrate with its surroundings, what materials it should be made from, etc. To achieve this, contextual architects suggest that some of the design process is carried out on the site where the house is going to be built $[1-3,6,9,29]$. As a specific technique for this, Alexander simply suggests that the architects place themselves in a particular spot of interest, close their eyes, and create a picture in their mind of what things should look like from there [10].

Evoking and facilitating imagination is a particularly important factor to consider if one wishes to enable ordinary homebuilders or renovators to participate in an architectural design process alongside architects, developers and builders with expert skills in working with physical building design. However, as this is challenging even for the best architects, it can be a significant obstacle for their clients. Especially when it comes to contextual architecture, exploring design alternatives through visual imagination can be very difficult for non-architecturally trained people. Therefore it is often not something 
that the future house owners or inhabitants of a building actively partake in-simply because they do not have the visual skills and experience of their professional counterparts.

The participants in our study strongly confirmed this obstacle for homebuilders and renovators when trying to participate actively in the process. Some participants found it difficult to imagine the visual exterior of the house, and many found it difficult to imagine the appearance of the house in the context of its surroundings. But most importantly, everyone found it difficult to shape their visual imagination of either of these solely on the basis of 2D drawings and blueprints.

In response to this challenge, we experienced that ArchiLens was able to evoke visual imagination by bringing people's un-built houses "alive" so to speak. This experience of aliveness stemmed from two things, namely that the visualisation took place on site with a one-to-one mapping between the physical and the virtual world, and that the visualisation was interactive and enabled people to consider alternative choices and share and discuss opinions right where the those designs were going to be situated. In several cases, this led to our participants achieving an improved understanding of the spatial layout and visual characteristics of their future house. They were also able to imagine better what it would look like in reality and how it would interrelate with its context. While our participants generally had some imagination about their un-built house beforehand, exploring it through ArchiLens helped in extending this imagination and making it more concrete and complete.

While we have explored the use of AR technology in house development and design, work practices today in house developments typically involve more "traditional" approaches and technologies, e.g. 2D and 3D models on desktop computers. While we haven't conducted any comparative studies of our approach compared to these traditional approaches, it is obvious that they exhibit different opportunities and limitations. The limited screen size, the lower screen resolution, and more limited input and output facilities, makes certain activities more difficult when using ArchiLens. As an example, it is probably easier (and perhaps also faster) to get an overview of the entire house as a whole. This would be rather difficult when using ArchiLens. However, we need further studies to highlight and understand the comparative opportunities and limitations of the different approaches.

Another challenge for active participation in the design process that is related to visual imagination is the coordination and adjustment of this imagination among the different people involved. This can be described as a challenge of achieving common ground through co-experience. As co-experience relies heavily on communication based in shared experiences [30], this is particularly difficult to achieve if the shared object of imagination does not have a physical form, or a representation understood, at least partly, by everyone involved. In relation to this, our participants expressed that they would like to share and develop ideas with the architect, the builder, their partner, and their family, but that they often found it difficult to express their imagination clearly enough for a shared understanding to be reached. From this perspective, providing visual 3D representations in context, like the ones in ArchiLens, becomes a means for aligning different people's imagination by enabling co-experience of something virtual and providing a boundary object [31] for communication.

\subsection{Enabling participation in contextual architecture}

One of our guiding motivations for developing ArchiLens was a belief in the value of contextual architecture as a design philosophy combined with a wish to enable a larger degree of "end user" participation in it. Just like we believe in participatory design of computer systems (e.g. [32]), we believe that there is important value to be gained from enabling people to participate actively in the design and development of the physical spaces that they inhabit. In this sense, we aimed to support future house owners (house builders) in architectural work and creation by letting them use ArchiLens in context. Thus, we seek to enable contextual architecture.

In this particular study we have explored the use of augmented reality as a specific candidate emerging technology for enabling such participation. Based on our findings, this approach appears to have some merit, both technologically and in terms of the user experience created.

The ArchiLens system illustrates how the design philosophy of contextual architecture can be supported through the use of a new but widely available technology by enabling a highly iterative exploration of the interplay between buildings and their surroundings. From the perspectives of architectural theory described earlier, what a system like ArchiLens does is to allow the users to develop and exercise a higher level of genius loci $[2,8]$ in their response to the topographical, geographical, social and cultural context of the building site. Not only does it require the users to be present in the context of the building site, and allow them to see what the future building will look like, it also allows them to make immediate changes on site in response to what they experience, thereby making the response to the environment much more iterative and direct. From the perspective of Alexander's principle of wholeness preserving transformations [9], which describes good designs as those that with deep respect for the existing context transform an existing space into a new one while preserving its original quality of wholeness, the important thing about systems like ArchiLens is that they allow for an iterative exploration and assessment of a selection of possible transformations of a space by situating form in context without materialising it in a structure that is difficult, expensive, or impossible to modify-or remove.

While using ArchiLens in context, our participants made decisions or gave comments that could also be personally motivated as well as context motivated, e.g. the decision to use yellow bricks rather than black bricks for some of the participants. While they did state that the yellow bricks fitted better with the context (surroundings), they also indicated that this colour was a personal preference. Thus, in some situations, context and personal motivations blended together. 
The study of ArchiLens illustrates that putting such technology in the hands of ordinary homebuilders or renovators not only facilitated them practicing aspects of contextual architecture. It also enabled them to participate more actively in the architectural design process in collaboration with the architects and builders as a result of this. Without any sod being cut, and without a single brick being laid in mortar, they were able to explore genius loci in the design of their future homes, and they were able to identify which design options would transform the space without violating its existing qualities of wholeness.

\section{Conclusions}

We have explored the potentials of using mobile phones for enabling ordinary homebuilders or renovators to participate more actively in the parts of an architectural design process that take place on the building site. For this purpose we have described a mobile AR system called ArchiLens, which was designed and implemented for on-site interactive 3D visualisation of private homes. We have also described a field study with 40 participants in the process of building or modifying their home who used ArchiLens for exploring their design, and making changes to it, on site in its future physical surroundings.

The study showed that interacting with the system helped evoke people's imagination and envisage the look and feel of their future house. This enabled them to participate more closely in the design process on-site by interactively reviewing design alternatives and exploring, for example, other placements and materials. Through ArchiLens non-architecturally trained people were able to envisage and better understand the interplay between their house and its context. The system gave them the ability to change plans, location, orientations, materials and facades, and thereby exert a degree of genius loci in iteratively responding to the topographical, geographical, social and cultural context of their building site. As a result of this they were able to allow that context to influence the evolution of harmonious and compatible design features and shaping a house design suiting that particular environment.

Using the example of facilitating participatory contextual architecture with mobile phones, the study illustrates how new technology can be used to enable people's participation in important activities and decision-making processes, that would otherwise be difficult or out of reach. We hope this will inspire other similar efforts of facilitating participation within other domains.

\section{Further work}

Several avenues for further research seem apparent after our study. First we acknowledge the possible value of a bigger display for interactive visualisation of future architecture in context. Especially when looking at the use of a system like ArchiLens as a social act, sometimes involving whole families, a larger display would be preferred simply to allow more people a better view at a time. With the emergence of tablet computers with rear-facing cameras, these would be an obvious choice of platform to explore for a follow-up study. In order to further investigate the impact of systems like ArchiLens in relation to decision-making in the architectural design process, a longitudinal study of use would be beneficial. While several indicators of impact on crucial design decisions were observed in our field study, the relative short duration of the study, in light of the typical time-span of a house building or renovation project, made it difficult to make definitive conclusions about this. Also, it would be interesting to investigate how larger development projects, e.g. re-building parts of a city, could be pursued. It is not clear how large-scale projects are actually suited for such AR technology. Finally, further investigation of the social co-experience facilitated by systems like ArchiLens would be fruitful for informing future designs. On the technical side, we encourage the investigation of ways for improving the accuracy of the system, such as the use of physical markers, however with particular attention to the trade-off in user experience between precise graphics and unrestricted user mobility.

\section{Acknowledgements}

We would like to thank all participating families in the field studies. Further, we would like to thank Vendia-Huset for their active collaboration in the project. Finally, we would like to thank several reviewers and colleagues for comments on earlier versions of the paper.

\section{References}

[1] B.C. Brolin, Architecture in Context: Fitting New Buildings with Old, Van Nostrand Reinhold, New York, 1980.

[2] P. McGillick, K. Carlstrom, Alex Popov: Buildings and Projects, Axel Menges, 2002.

[3] K. Ray, Contextual Architecture: Responding to Existing Style, McGraw-Hill, New York, 1980.

[4] W. Piekarski, B.H. Thomas, Interactive augmented reality techniques for construction at a distance of 3D geometry, in: EGVE'03, ACM, New York, NY, USA, 2003, pp. 19-28.

[5] A. Morrison, A. Oulasvirta, P. Peltonen, S. Lemmelä, G. Jacucci, J. Reitmayr, A. Juustila, Like bees around the hive: a comparative study of a mobile augmented reality map, in: Proc. CHI'09, ACM Press, Boston, USA, 2009, pp. 1889-1898.

[6] A.J. Summerfield, S. Hayman, On capturing context in architecture, Dept. of Architectual Design Science-University of Sydney, 2006.

[7] G. Shane, Contextualism, Architectural Design 46 (11) (1976) 676-679.

[8] C. Norberg-Schulz, Genius Loci: Towards a Phenomenology of Architecture, Rizzoli, New York, 1980.

[9] C. Alexander, The Nature of Order, vols. 1-4, CES Publishing, Berkeley, California, 2002-2005. 
[10] C. Alexander, S. Ishikawa, M. Silverstein, A Pattern Language, Oxford University Press, New York, 1977.

[11] T.H. Höllerer, S.K. Feiner, Mobile augmented reality, in: Karami, Hammad (Eds.), Telegeoinformatics: Location-Based Computing and Services, Tayler and Francis Books Ltd., 2004

[12] R.T. Azuma, A survey of augmented reality, Presence: Teleoperators and Virtual Environments 6 (4) (1997) $355-385$.

[13] R. Wojciechowski, K. Walczak, M. White, W. Cellary, Building virtual and augmented reality museum exhibitions, in: Web3D'04, ACM, New York, NY, USA, 2004, pp. 135-144.

[14] S. Feiner, B. MacIntyre, T. Höllerer, A. Webster, A touring machine: prototyping 3D mobile augmented reality systems for exploring the urban environment, in: ISWC'97, pp. 74-81.

[15] S.K. Feiner, Augmented reality: a new way of seeing, Scientific American 286 (4) (2002) 48-55

[16] T. Miyashita, P. Meier, T. Tachikawa, S. Orlic, T. Eble, V. Scholz, A. Gapel, O. Gerl, S. Arnaudov, S. Lieberknecht, An augmented reality museum guide, in: ISMAR'08, IEEE Computer Society, Washington, DC, USA, 2008, pp. 103-106.

[17] G. Reitmayr, D. Schmalstieg, Location based applications for mobile augmented reality, in: AUIC'03, Australian Computer Society, Inc., Darlinghurst, Australia, Australia, 2003, pp. 65-73.

[18] G. Reitmayr, D. Schmalstieg, Collaborative augmented reality for outdoor navigation and information browsing, in: Symposium on Location-Based Services and TeleCartography, 2004, pp. 31-41.

[19] S. White, S. Feiner, Sitelens: situated visualization techniques for urban site visits, in: Proc. CHI'09, ACM Press, Boston, USA, 2009 , pp. 1117-1120.

[20] T.P. Caudell, D.W. Mizell, Augmented reality: an application of heads-up display technology to manual manufacturing processes, in: Proceedings of 1992 IEEE Hawaii International Conference on Systems Sciences, IEEE Press, 1992.

[21] D.W. Mizell, Virtual reality and augmented reality for aircraft design and manufacturing, in: Boeing Information and Support Services, The Conference of WESCON/94 Idea/Microelectronics, 1994.

[22] Y. Guo, Q. Du, Y. Luo, W. Zhang, L. Xu, Application of augmented reality gis in architecture, in: ISPRS VIII, 2008.

[23] G. Schall, E. Mendez, E. Kruijff, E. Veas, S. Junghanns, B. Reitinger, D. Schmalstieg, Handheld augmented reality for underground infrastructure visualization, Personal and Ubiquitous Computing 13 (4) (2009) 281-291.

[24] T. Gleue, P. Dähne, Design and implementation of a mobile device for outdoor augmented reality in the archeoguide project, in: VAST'01, ACM, New York, NY, USA, 2001, pp. 161-168.

[25] Wikitude, 2010. www.wikitude.org (accessed on 22.09.11)

[26] Layar, 2010. www.layar.com (accessed on 22.09.11).

[27] S.M. Bozic, Digital and Kalman Filtering, Butterworth-Heinemann, 1994

[28] A. Strauss, J. Corbin, Basics of Qualitative Research-Techniques and Procedures for Developing Grounded Theory, SAGE Publications, Thousand Oaks, 1998.

[29] K. Lynch, The Image of the City, The MIT Press, Cambridge, Massachusetts, 1960.

[30] K. Battarbee, Co-experience: the social user experience, in: Proceedings of the Conference on Human Factors in Computing Systems, CHI'03, ACM Press, 2003, pp. 730-731.

[31] S.L. Star, J.R. Griesemer, Institutional ecology, 'translations' and boundary objects, Social Studies of Science 19 (3) (1989) 387-420.

[32] F. Kensing, J. Blomberg, Participatory design: issues and concerns, Computer Supported Cooperative Work 7 (1998) $167-185$. 